\title{
ON THE HOLOTYPE OF Cnemaspis podihuna DERANIYAGALA, 1944
}

\section{A. A. Thasun Amarasinghe ${ }^{1}$ and Aaron M. Bauer ${ }^{2}$}

\footnotetext{
${ }^{1}$ Taprobanica Nature Conservation Society, 146, Kendalanda, Homagama, Sri Lanka E-mail: aathasun@gmail.com

${ }^{2}$ Department of Biology, Villanova University, 800 Lancaster Avenue, Villanova, Pennsylvania 19085-1699, USA. E-mail: aaron.bauer@villanova.edu
}

Sri Lankan members of the gecko genus Cnemaspis Strauch, 1887 have recently been reviewed and redescribed (Wickramasinghe \& Munindradasa 2007; Manamendra-Arachchi et al. 2007). The endemic species Cnemaspis podihuna was first described by P. E. P. Deraniyagala in 1944 from LahugalaMaha Oya area in Eastern Province based on five specimens (holotype and four paratypes). Deraniyagala (1944) clearly stated "Type - An adult male (fig. I) with the distal half of the tail broken off. Length....; tail (incomplete) $18 \mathrm{~mm}$. The specimen is in the Colombo Museum." He also mentioned "Paratypes - An adult female measuring $25 \mathrm{~mm}$. from snout tip to cloaca (tail missing), a half grown specimen, and two young ones." The original description includes a figure of $C$. podihuna (see Amarasinghe et al., 2009 for the original figure and original description); this is almost certainly intended to be of the type based on the fact that the figure shows precloacal and femoral pores, a feature restricted to mature male Cnemaspis, and on the basis that the holotype was the only adult male noted by Deraniyagala. Deraniyagala (1953) subsequently provided the same information again in his book-length treatment of the lizards of Sri Lanka.

After 54 years with no further explicit literature reports of $C$. podihuna, Wickramasinghe (2000) rediscovered the species at Koslanda in the Badulla District, noting five specimens (NMSL RG 21). Wickramasinghe \& Munindradasa (2007) collected four additional specimens (NMSL20061001, NMSL20061002, NMSL20061003, NMSL20061004) from Lahugala near Siyabalanduwa $\left(06^{\circ} 52^{\prime} 55.9^{\prime}\right.$ N, $81^{\circ} 42^{\prime} 30.2^{\prime \prime} \mathrm{E}$; alt. $387 \mathrm{~m}$ ).

Kandamby (1997) mentioned that the type of $C$. podihuna was present as an uncatalogued specimen at the National Museum of Colombo, Sri Lanka. However, according to Wickramasinghe \& Munindradasa (2007) "The voucher specimen deposited in National Museum Sri Lanka (NMSL) in place of the misplaced type specimen of $C$. 
podihuna differs in morphological detail to the type description as well as to the morphometric parameters of specimens collected from the type locality. The above specimen belongs to $C$. molligodai sp. nov. of the present study, hence the neotype of C. podihuna (NMSL20061001) is deposited." They designated a neotype (NMSL20061001) and three syntypes (NMSL20061002, NMSL20061003, NMSL20061004) for C. podihuna. This action was criticized and considered as erroneous and invalid according to the ICZN by Pethiyagoda (2007) and Manamendra-Arachchi et al. (2007) who rediscovered the presumed holotype of C. podihuna (see plate 5a. of Manamendra-Arachchi et al., 2007 and note the presence of complete tail) and redescribed it.

Under Article 75.8 of the International Code of Zoological Nomenclature, 1999 this rediscovered holotype invalidates the earlier neotype designation and again assumes the role as the name-bearer for the taxon.

Pethiyagoda (2007) states that ManamendraArachchi et al. (2007) ".....found that it [the presumed rediscovered holotype] is entirely consistent with the original description: .....". Pethiyagoda also states "when examined in 1994 the label in the jar containing the holotype read 'Cnemaspis podihuna TYPE' under which was written 'RAS 1944 XXXVI p. 226'. The upper part of the label has since torn off, leaving only the lower portion that reads 'RAS 1944 XXXVI $p$. 226 , which is reference to the volume and page of the Journal of the Royal Asiatic Society (Ceylon Branch) in which the original description was published."

However the same specimen which was rediscovered as the holotype of $C$. podihuna was examined in 2004 by the second author of this paper. At that time it was accompanied by a label (fig. 01) stating that it had been collected in 1960 from Hunwala, that it had been identified by Kelum Manamendra-Arachchi.

We do not know where the confusion originated, but if this label is correct with respect to date of collection and locality, it is evident that the specimen illustrated by Manamendra-Arachchi et al. (2007) cannot be Deraniyagala's holotype. Further, the number of femoral pores and the number of scales separating femoral and preanal pores from one another in this specimen (as illustrated in Figure 20f of Manamendra-Arachchi et al. (2007) (4 and 7, respectively) does not match that illustrated and described by Deraniyagala (1944) (5 and 6, respectively).

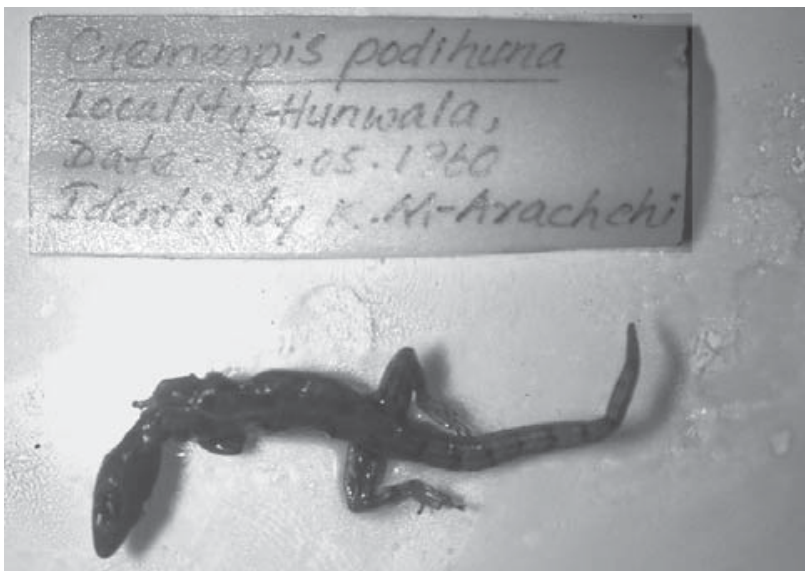

Fig. 01: Specimen of C. podihuna observed by A. Bauer in 2004 .

A specimen labeled as the holotype of $C$. podihuna is present at The Natural History Museum, London under registration number BMNH 1946.8.1.20 (see plate 02: fig. 09 of Amarasinghe et al., 2009) and is associated with the locality "Luhugala, Eastern Province, Ceylon". Data with the specimen indicate that it was presented by the Colombo Museum and the registration number shows that it entered the collection in London on $01^{\text {st }}$ August, 1946. There is also a note in the BMNH catalogue that indicates: "description tallies with the type apart from snout to ear tip measurement." Our recent observations on this specimen confirm that its SVL and axilla to groin measurements are indeed a close match to the type of $C$. podihuna as described by Deraniyagala: SVL $25 \mathrm{~mm}$ (vs. $26 \mathrm{~mm}$ ), axilla to groin $11.5 \mathrm{~mm}$ (vs. $12 \mathrm{~mm}$ ). The tail length of BMNH 1946.8.1.20 is only $2.5 \mathrm{~mm}$, but this may reflect the subsequent damage or loss of most of the $18 \mathrm{~mm}$ broken tail described by Deraniyagala (1944). Only the snout tip to tympanum measurement of the specimen, 6.5 $\mathrm{mm}$ vs. $8 \mathrm{~mm}$, is not a good match to the holotype mensural features. Likewise, this specimen has 5 femoral pores on each thigh, again consistent with the type description. However, it appears to have 6, rather than 4 preanal pores.

Thus we are left with two claimants to the position of holotype for Cnemaspis podihuna. The Colombo specimen differs in presence of complete tail and number of femoral pores from the type and, at least in 1994, was in a jar with a label indicating that its date of collection and provenance were 
incompatible with Deraniyagala's type. The BMNH specimen differs in the number of preanal pores and contradicts Deraniyagala's statement that the holotype was in the Colombo Museum (although it is possible that the type was either purposely or inadvertently given as a gift by Deraniyagala, who was director of the museum in Colombo at the time). On the basis of existing information it is not possible to unambiguously determine which, if either, of these two specimens is the real holotype of C. podihuna. Indeed, unless some of Deraniyagala's (1944) description is inaccurate, it would appear that neither specimen can be an exact match to the type. Regardless of this, it appears as if the two contenders are conspecific and that there is no real confusion over the identity of $C$. podihuna. Thus, even if we consider the true holotype to be lost, under Article 75.3 of the Code, the conditions for the justification of neotype designatations are not met in this circumstance and the action of Wickramasinghe \& Munindradasa (2007) in this regard is nonetheless invalid.

The case of Cnemaspis podihuna highlights the need for the unambiguous labeling of all specimens, but especially types. Over time sources of data may become lost or misplaced and labels, if not attached, may easily become dissociated from the specimens they were originally meant to identify.

\section{Acknowledgements}

We express our gratitude to Colin McCarthy for kindly taking photographs of types and providing valuable comments.

\section{Literature Cited}

Amarasinghe, A. A. T., A. M. Bauer, I. Ineich, J. Rudge, M. M. Bahir and D. E. Gabadage, 2009. The original descriptions and figures of Sri Lankan gekkonid lizards (Squamata: Gekkonidae) of the $18^{\text {th }}, 19^{\text {th }}$ and $20^{\text {th }}$ centuries. Taprobanica, 1 (2): 83-106.

Deraniyagala, P. E. P., 1944. A new Cnemaspis gecko from Ceylon. Journal of Royal Asiatic Society (Ceylon Branch), XXXVI: 226-227.

Deraniyagala, P. E. P., 1953. A Colored Atlas of some vertebrates from Ceylon, Tetrapod Reptilia, Vol. 02. National Museums of Sri Lanka, Colombo: vii+101+46 pls.

Kandamby, D., 1997. Herpetological types reposed in the National Museum Colombo, Sri Lanka. Lyriocephalus, 3 (1): 31-33.
Manamendra-Arachchi, K., S. Batuwita, and R. Pethiyagoda, 2007. A taxonomic revision of the Sri Lankan day-geckos (Reptilia: Gekkonidae: Cnemaspis), with description of new species from Sri Lanka and southern India. Zeylanica, 7 (1): 9-122.

Pethiyagoda, R., 2007. The 'New Species Syndrome' in Sri Lankan herpetology: a cautionary note. Zeylanica, 7 (1): 1-7.

Wickramasinghe, L. J. M., 2000. A New Record of Cnemaspis podihuna from Badulla District. Sri Lanka Naturalist, 3 (1): 3-6.

Wickramasinghe L. J. M. and D. A. I. Munindradasa, 2007. Review of the genus Cnemaspis Strauch, 1887 (Sauria: Gekkonidae) in Sri Lanka, with the description of five new species. Zootaxa, 1490: 1-63. 